\title{
MALDI and LDI Imaging of Forensic Samples by Using A Spiral-Trajectory Ion Optics Time-of-Flight Mass Spectrometer
}

\author{
Masaaki Ubukata ${ }^{1}$, A. John Dane ${ }^{1}$, Robert B. Cody ${ }^{1}$, Donna Guarrera ${ }^{1}$, David C. Edwards ${ }^{1}$, Natasha \\ Erdman $^{1}$, Masateru Shibata ${ }^{1}$, Takaya Satoh $^{2}$ \\ 1. JEOL USA, INC., Peabody, MA, USA \\ 2. JEOL Ltd., Akishima, Japan
}

Recently, matrix-assisted laser desorption/ionization (MALDI) imaging techniques have been developed for biological sciences to evaluate and understand the distribution of various chemicals on biological surfaces. In particular, this technique provides useful visual information about the locations of specific chemicals on surfaces.

In this work, we explored the use of MALDI imaging for forensically relevant samples that included gunshot residue (GSR), fingerprints and ballpoint ink. These measurements were done using a spiraltrajectory ion optics time-of-flight mass spectrometer (SpiralTOF-MS [1]). This TOF system has a unique $17 \mathrm{~m}$ flight path that provides ultrahigh-resolution mass spectra over a wide $\mathrm{m} / \mathrm{z}$ range, even if the sample is not perfectly flat. Additionally, the $\mathrm{m} / \mathrm{z}$ axis is very stable over the long measurement times required for MALDI imaging.

GSR samples were obtained on an electrically conductive adhesive that was pressed against the back of a shooter's hand after a handgun was discharged. The fingerprint samples were collected on electrically conductive ITO glass slides from both a smoker and a non-smoker. The smoker's fingerprint was collected immediately after smoking a cigarette. 2,5-dihydroxybenzoic acid (DHB) was used as the MALDI matrix. This matrix was dissolved in methanol at a fixed concentration of $30 \mathrm{mg} / \mathrm{mL}$. 1-2 mL of DHB solution was sprayed on each sample surface by using a commercial airbrush. Samples were then analyzed by using a high-resolution MALDI-TOFMS instrument. A polypropylene glycol (PPG) mixture of average MW 425 and 1000 were used as an external exact-mass reference standard.

The GSR sample surface was analyzed for inorganic element distributions. As a starting point, we evaluated the mass accuracy of the SpiralTOF-MS with external calibration using two different DHB ions, $\mathrm{C}_{7} \mathrm{H}_{5} \mathrm{O}_{3}{ }^{+}$and $\mathrm{C}_{7} \mathrm{H}_{6} \mathrm{O}_{4} \mathrm{Na}^{+}$, in the measured spectrum. Because their monoisotopic ions were saturated, the $[\mathrm{M}+1]$ isotope ions were used, and the calculated mass error for each was $+6.4 \mathrm{mDa}$ and $5.1 \mathrm{mDa}$, respectively. As a result, it was not necessary to use internal calibration for qualitative MALDI imaging measurements on the SpiralTOF-MS. Afterwards, the inorganic particle distributions for barium, barium oxide, lead, bismuth, calcium oxide, etc. were selected for imaging on the surface. As it turns out, the ${ }^{138} \mathrm{Ba} \mathrm{m} / \mathrm{z} 137.9016$ has a similar mass to the DHB [M+1] isotopic ion $\mathrm{m} / \mathrm{z}$ 138.02671 $\left(\mathrm{C}_{7} \mathrm{H}_{5} \mathrm{O}_{3}\right)$. Although the difference in their mass values is only 0.125 Da, the SpiralTOF-MS provided full separation for both ion peaks which in turn produced completely different images for each analyte on the surface. The distribution of the ${ }^{138} \mathrm{Ba} \mathrm{m} / \mathrm{z} 137.9016$ was randomly distributed across the surface while the DHB $\mathrm{m} / \mathrm{z} 138.02671$ was homogeneously present across the matrix surface.

Next, we examined the nicotine distribution on both a smoker's and non-smoker's fingerprints (Figure 1). We focused on determining the chemical composition of the observed $\mathrm{m} / \mathrm{z} 163.1224$ on the fingerprint by using the accurate mass values with internal calibration method. DHB matrix ions were used as the internal calibrant for this accurate mass measurement. The mass error of the $\mathrm{m} / \mathrm{z} 163.1224$ was just $-0.6 \mathrm{mDa}$ when compared to the protonated molecule of a nicotine standard $(\mathrm{m} / \mathrm{z} 163.1230$, $\mathrm{C}_{10} \mathrm{H}_{15} \mathrm{~N}_{2}$ ) using internal calibration. There was a strong nicotine distribution on the smoker's 
fingerprint that was not detected on the non-smoker's fingerprint. This is a very reasonable result considering the fact that the smoker is exposed to nicotine when smoking.

The ballpoint ink samples (Figure 2) were subjected to a gold vapor deposition in order to improve the conductivity of the paper. No matrix was added to this sample surface (LDI imaging). The ink consisted of crystal violet as the main component and was easily detected directly on the surface of the handwriting sample with the gold vapor deposition.

[1] T. Satoh, T Sato, A. Kubo, J. Tamura, J. Am. Soc. Mass Spectrom. 22(2011) 797-803

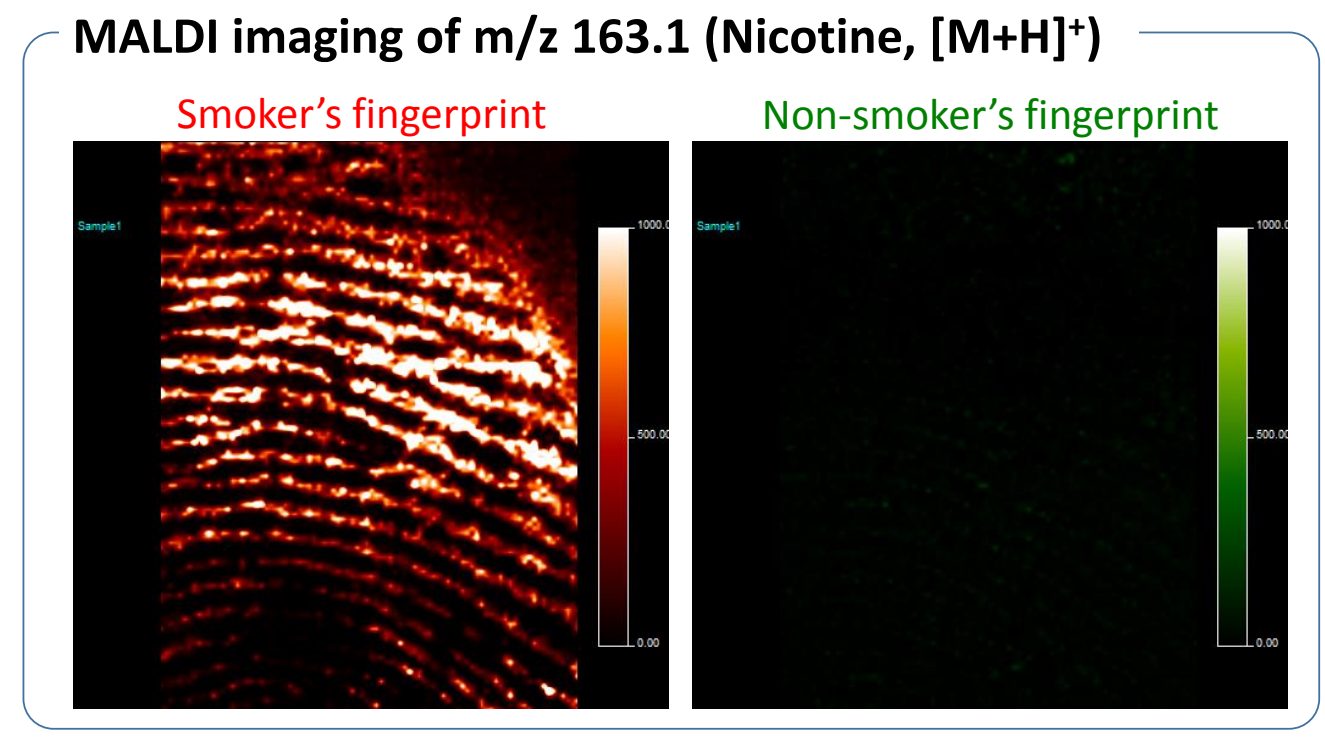

Figure 1. MALDI imaging of protonated nicotine on both smoker's and non-smoker's fingerprints.
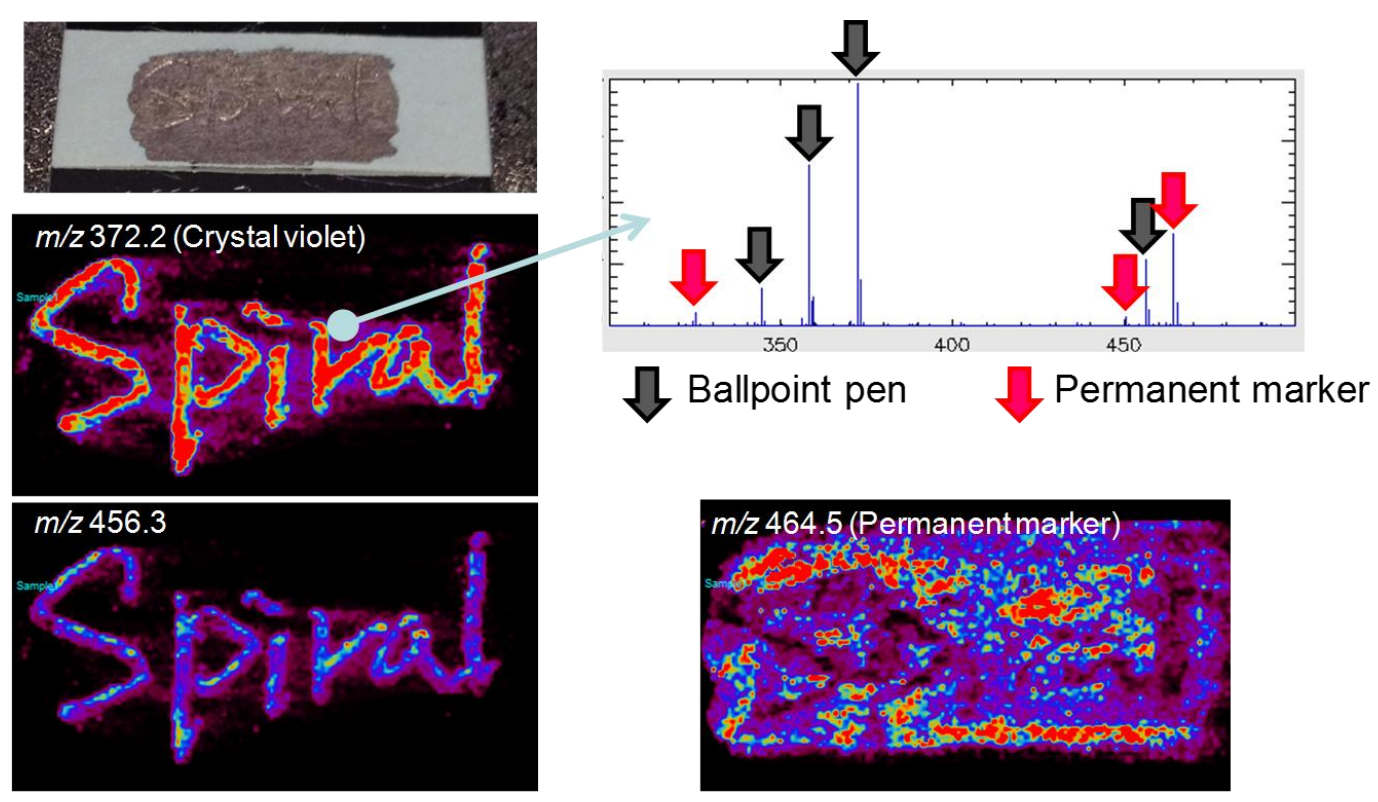

Figure 2. Imaging of hidden organic dyes for ballpoint pen ink obliterated with permanent marker. 